\title{
Diversity and bioethics
}

\author{
Henk ten Have $\cdot$ Bert Gordijn
}

Published online: 7 June 2011

(C) Springer Science+Business Media B.V. 2011

In a recent edition of Foreign Affairs Princeton professor John Ikenberry argues that the liberal international order is alive and well (Ikenberry 2011). The global political order of today is characterized by openness and rule-based relations enshrined in institutions such as the United Nations and norms such as multilateralism. This order has been constructed in the West. Some fear that non-Western developing countries will not share this order. Perhaps they will use the current political and economic changes to introduce more traditional and autocratic approaches. Ikenberry rejects such fears. First, he argues that today's international order is the result of centuries of struggle and innovation around the world, and thus not simply the product of the West. The notions of state sovereignty and self-determination have in fact encouraged political movements for decolonization and independence in the developing world. The international community has established supra-national institutions as well as elaborated the universal rights of man. The modern international order is therefore not American or Western but much wider. The hegemonic organization of this order may change but not its fundamental principles. Second, emerging states as Brazil, China and India have themselves deep interests in an open and rule-based international order. Countries' positions within the system will be renegotiated. But the rules and institutions of the order will continue to be embraced, or so Ikenberry argues. Of course there is also growing awareness of global interdependence, demonstrating the need and even further development of multilateral rules and institutions. The same challenges are faced

H. ten Have $(\square) \cdot$ B. Gordijn

Duquesne University, Pittsburgh, PA, USA

e-mail: tenhaveh@duq.edu by developed as well as developing countries, viz. climate change, pandemic diseases, disasters, and terrorism. They can only be addressed through cooperation and solidarity.

This view of globalization is immediately relevant for global bioethics. In this area we also have the continuous tension between universalism and particularism, globalism and localism. On the one hand, universal principles are formulated and endorsed by international bodies. On the other, principles need to be applied in various contexts and settings. It is an easy strategy to mitigate and deny the tension by arguing that bioethics is a western product or that bioethics is imposing so-called universal principles on other cultures and traditions mostly in non-western countries. These strategies of denial are clearly at work when the notion of diversity is discussed, as Bracanovic demonstrates in his contribution to the current issue of Medicine, Health Care and Philosophy (Bracanovic 2011). In order to respect existing diversity in values and norms, the principle of respect for cultural diversity and pluralism has been incorporated in the Universal Declaration on Bioethics and Human Rights, which has been adopted by the Member States of UNESCO in 2005. This principle, as advanced in article 12 of the UNESCO Declaration, is therefore one of the 15 fundamental principles of global bioethics. At the same time, it is the only principle of the Declaration for which the hierarchical status is determined. Article 12 explicitly states that considerations of diversity cannot be invoked to justify infringements of human dignity and human rights, or any other principle of the Declaration (UNESCO 2005). In the balancing of principles, this particular principle therefore is the weakest one. But nonetheless, for the first time in bioethics, respect for diversity has been formulated as a specific principle that should be taken into account in the assessment of ethical issues and problems. 
There are several reasons why the interest in diversity in bioethics has emerged. Bracanovic criticizes both this interest as well as the consideration that diversity should be taken into account. Cultures are notoriously difficult to interpret. At the same time, the moral relevance of cultural differences is not always articulated. Bracanovic does not seem to make much difference between religious and cultural phenomena. His examples of moral relevant differences are all concerned with different religious conceptions and views. In our view cultures are complex and not monolithic. This is also true for the Western culture in which bioethics has emerged. Within this culture tensions exists between individual autonomy and the role of community. European bioethics therefore is not the same as American bioethics. Even within Europe significant differences prevail in approaching ethical issues so that some colleagues would even argue that Mediterranean bioethics is as different from Nordic bioethics as for instance an Italian Catholic differs from a Dutch one. This heterogeneity makes it very difficult to apply the principle of respect for diversity. One cannot only act upon imprecise generalizations. This difficulty, however, does not imply that cultural differences are identical to individual differences. But it raises the question how much individual views are determined by cultural ones. Respect for cultural diversity depends also on the weight that we give to the role of the individual person (which is itself a point of view that is heavily determined by a specific liberal cultural stance). Communitarians for example argue that more moral weight should be given to the role of the community in ethical decision-making. We can safely predict that the role of diversity will continue to be discussed with the further globalization of bioethics. It will, for example, be the main theme of the 8th International Conference on Clinical Ethics \& Consultation, organized in Sao Paulo, Brazil, in May 2012.

\section{References}

Bracanovic, T. 2011. Respect for cultural diversity in bioethics. Empirical, conceptual and normative constraints. Medicine, Health Care and Philosophy (this issue).

Ikenberry, G.J. 2011. The future of the liberal world order. Internationalism after America. Foreign Affairs 90(3): 56-68.

UNESCO. 2005. The universal declaration on bioethics and human rights. http://unesdoc.unesco.org/images/0014/001461/146180E. pdf. 